\title{
CoronaVac Aşısının İkinci Dozu COVID-19 Geçirmiş Kişilerde Antikor Düzeylerinin Düşmesine Neden Olabilir
}

\author{
The Second Shot of CoronaVac Vaccine May Cause Reduction \\ of Antibody Levels in People who Previously had COVID-19
}

\author{
Aynur Eren TOPKAYA ${ }^{1}\left(\right.$ ID), Ali Ümit KESKIN²(ID), Altay Burak DALAN(ID), Pınar ÇIRAGiL ${ }^{1}($ ID $)$ \\ ${ }^{1}$ Yeditepe Üniversitesi Tıp Fakültesi, Tıbbi Mikrobiyoloji Anabilim Dalı, İstanbul. \\ ${ }^{1}$ Yeditepe University Faculty of Medicine, Department of Medical Microbiology, Istanbul, Turkey. \\ ${ }^{2}$ Yeditepe Üniversitesi Mühendislik Fakültesi, Biyomedikal Mühendisliği Anabilim Dalı, İstanbul. \\ ${ }^{2}$ Yeditepe University Faculty of Engineering, Department of Biomedical Engineering, istanbul, Turkey. \\ ${ }^{3}$ Yeditepe Üniversitesi Tıp Fakültesi, Tıbbi Biyoloji Anabilim Dalı, İstanbul. \\ ${ }^{3}$ Yeditepe University Faculty of Medicine, Department of Medical Biology, Istanbul, Turkey.
}

Makale Atıfı: Topkaya AE, Keskin AÜ, Dalan AB, Çıragil P. CoronaVac aşısının ikinci dozu COVID-19 geçirmiş kişilerde antikor düzeylerinin düşmesine neden olabilir. Mikrobiyol Bul 2021;53(2):139-142.

\begin{abstract}
The CoronaVac vaccine is an inactivated type two-dose regimen vaccine developed and manufactured by Sinovac Life Sciences Company, in China. It has already been used in China's vaccination program, while 21 other countries (including Indonesia, Turkey and Brazil) also granted emergency use authorization for this vaccine. In Turkey, on January 14, 2021, healthcare workers (HCWs) started to be vaccinated with CoronaVac as the priority group in vaccination. An important question that arose at this time was about how the vaccination schedule would be for people who had previously had Coronavirus disease 2019 (COVID-19). The Centers for Disease Control and Prevention (CDC) recommends that those who have had a previous COVID-19 infection can be vaccinated regardless of their previous infection. CDC guidelines also mention that "...if antibody (Ab) testing was done after the first dose of an mRNA vaccine, the vaccination series should be completed regardless of the Ab test result". It should be noted here that this statement applies particularly to mRNA type vaccines, whereas CoronaVac jab is an inactivated type two-dose regimen vaccine. The aim of this study was to present interim results of our ongoing study to compare the effect of two doses of inactivated CoronaVac vaccine on humoral immunity of people who had previously severe acute respiratory syndrome coronavirus-2 (SARS-CoV-2) infection, and those people who did not have the infection. In our study, CoronaVac jab containing 600 SU inactivated SARS-CoV-2 antigen was administered as $0.5 \mathrm{ml}$ to $62 \mathrm{HCWs}$ in Yeditepe University Hospital (Istanbul, Turkey), in accordance with the manufacturer's recommendations. Ab levels against spike receptor binding region of SARS-CoV- 2 were measured quantitatively. SARS-CoV- 2 IgG assay were performed using Abbott Architect i2000 instrument (Abbott Laboratories, Abbott Park, IL, USA). Ab titers were measured before vaccination (Ab0), one month after the first vaccination $(A b 1)$, and one month after the second vaccination (Ab2). The Ab responses of $62 \mathrm{HCWs}$ before and after CoronaVac vaccination were determined. Two groups were created. Group 1 consisted of 18 females and 15 males
\end{abstract}


who were tested as COVID-19 positive, previously. Group 2 consisted of 20 females and 9 males who never had the infection. Minimum, median and maximum Ab0 values of Group1 were 1.6, 180.8 and 5582.6, respectively and Ab1 values were 26.3, 1005.7 and 3923.1; Ab2 values were 202.1, 1119.1 and 2885.9, (in au/mL) respectively. On the other hand, minimum, median and maximum Ab0 values of Group 2 were 0.1, 1.8, and 37.2, Ab1 values were 4.7, 72.7, 470.2, and Ab2 values were 270.3, 746.2 and 5554.1, respectively. In Group 1, 20 of the HCWs showed lower Ab2 titers, while 13 of the HCWs showed higher Ab2 titers than the Ab1 titers. Whereas in Group2 all HCWs had higher Ab2 titers than the Ab1 titers. When the increasing and decreasing Ab2 titers of both groups were evaluated with the $2 \times 2$ contingency table and Fisher's exact chi-square test, a statistically significant difference was found between the groups $(p<0.001)$. As a result, we think that a single dose of CoronaVac vaccine similarly to mRNA vaccines can be administered to people who have had COVID-19 due to the possibility that the $A b$ levels measured after the first dose of vaccine will decrease after the second dose of vaccine.

Keywords: COVID-19; coronavac; spike antibody.

\section{Sayın Editör,}

CoronaVac aşısı, şiddetli akut solunum yolu sendromu koronavirüs-2 (SARS-CoV-2) virüsüne karşı Çin'de Sinovac Life Sciences Company tarafından geliştirilmiş, üretilmiş ve iki doz olarak acil kullanım izni almış inaktif tip bir aşıdır. Haziran 2021 tarihi itibariyle Dünya Sağlık Örgütü (DSÖ) tarafından acil kullanım izni verilen CoronaVac; Çin, Endonezya, Brezilya ve Türkiye'nin de içinde olduğu 21 ülkede acil kullanım izniyle aşılama programlarında kullanılmıştır ${ }^{1}$.

Türkiye'de 14 Ocak 2021 tarihinde sağlık çalışanları aşılamada öncelikli grup olarak CoronaVac ile aşılanmaya başlamıştır. Ancak bu dönemde Koronavirüs hastalığı 2019 (COVID-19) geçirenlerde aşı takviminin nasıl olacağı önemli bir soru olarak ortaya çıkmıştır. Hastalık Kontrol ve Korunma Merkezleri ["Centers for Disease Control and Prevention" (CDC)] önceden COVID-19 enfeksiyonu geçirmiş olanların önceki enfeksiyonlarına bakılmaksızın aşılanmalarını önermektedir. CDC rehberleri ayrıca "... bir mRNA aşısının ilk dozundan sonra antikor (Ab) test sonucundan bağımsız olarak aşı serisinin tamamlanması gerekir" demektedir². Ancak bu ifadenin özellikle mRNA tipi aşılar için geçerli olduğu belirtilmekte olup, iki doz uygulanan inaktif CoronaVac aşısı için henüz geçerliliği bilinmemektedir.

Tek doz mRNA aşısının uygulandığı 59 kişinin Ab sonuçlarının değerlendirildiği bir çalışmada, önceden COVID-19 enfeksiyonu geçirenlerde, enfeksiyonu geçirmeyenlere göre önemli ölçüde yüksek Ab düzeyleri olduğu bildirilmektedir ${ }^{3}$.

Ön baskı olarak yayımlanan bir başka çalışmada araştırmacılar, aynı zaman aralıklarında önceden Ab pozitif kişilerde, enfeksiyon geçirmeyen kişilere göre 10-20 kat daha fazla Ab seviyesi gözlemlemişlerdir. Bu çalışmada, tek doz mRNA aşısı olanlarda iki hafta sonra, iki doz aşılı olanlar kadar veya 10 katı daha yüksek Ab düzeyleri olduğu bildirilmiştir ${ }^{4}$.

Bir başka çalışmada ise, enfeksiyonu geçiren kişilere yalnızca tek doz mRNA aşısının yeterli olabileceği öne sürülmektedir ${ }^{5}$. Ancak bugüne kadar CoronaVac gibi inaktif aşılar için bu konuda literatürde herhangi bir veri bulunamamıştır. 
Çalışmamızda, sağlık çalışanı olup COVID-19 geçirmiş ve hiç COVID-19 geçirmemiş iki farklı grupta CoronaVac aşısının humoral bağışıklık üzerine etkileri karşılaştırılmıştır. Çaıışmamızda Yeditepe Üniversitesi Hastaneleri'nde çalışmakta olan 62 sağlık çalışanına 0.5 ml'de 600 SU SARS-CoV-2 antijeni içeren CoronaVac aşısı üretici önerileri doğrultusunda uygulanmıştır. Sağlık çalışanları; Grup 1: COVID-19 geçirmiş (18 kadın ve 15 erkek) ve Grup 2: COVID-19 geçirmemiş (20 kadın ve 9 erkek) olarak iki gruba ayrılmıştır. SARS-CoV2'nin anti-spike Ab seviyeleri (SARS-CoV-2 IgG-S) aşılamadan önce (Ab0), birinci dozdan bir ay sonra (Ab1) ve ikinci dozdan bir ay sonra (Ab2) olmak üzere üç kez Abbott Architect i2000 cihazında (Abbott Laboratories, Abbott Park, IL, ABD) kantitatif olarak ölçülmüştür.

COVID-19 geçirmiş olanların bulunduğu Grup 1'in sırasıyla minimum, medyan ve maksimum Ab0 değerleri: 1.6, 180.8, 5582.6, Ab1 değerleri 26.3, 1005.7, 3923.1 ve Ab2 değerleri 202.1, 1119.1, 2885.9 (au/ml) olarak ölçülmüştür. COVID-19 geçirmemiş 29 sağlık çalışanının (Grup 2) sırasıyla minimum, medyan ve maksimum Ab0 değerleri 0.1, 1.8, 37.2; Ab1 değerleri 4.7, 72.7, 470.2 ve Ab2 değerleri 270.3, 746.2, 5554.1 (au/ml) olarak saptanmıştır. Grup 1'de 20 kişide Ab2 titrelerinin Ab1 titrelerinden daha düşük olduğu saptanırken, 13 kişide ise Ab2 titrelerinin Ab1 değerlerine göre yükseldiği gözlenmiştir. Grup 2'nin tamamında ise Ab2 titrelerinin Ab1'den daha yüksek olduğu saptanmıştır (Şekil 1). Her iki grubun artan ve azalan Ab2 titreleri 22 durum tablosu ve Fisher'in kesin ki-kare testi ile değerlendirildiğinde, gruplar arasında istatistiksel olarak anlamlı bir fark bulunmuştur $(\mathrm{p}<0.001)$.

Sonuç olarak, COVID-19 geçirmiş olan kişilerde, birinci doz aşıdan sonra ölçülen Ab düzeylerinin, ikinci doz aşıdan sonra azalma olasıllı̆ı nedeniyle, bu kişilere de mRNA aşıları ile benzer şekilde tek doz CoronaVac aşısı uygulanabilir düşüncesindeyiz.

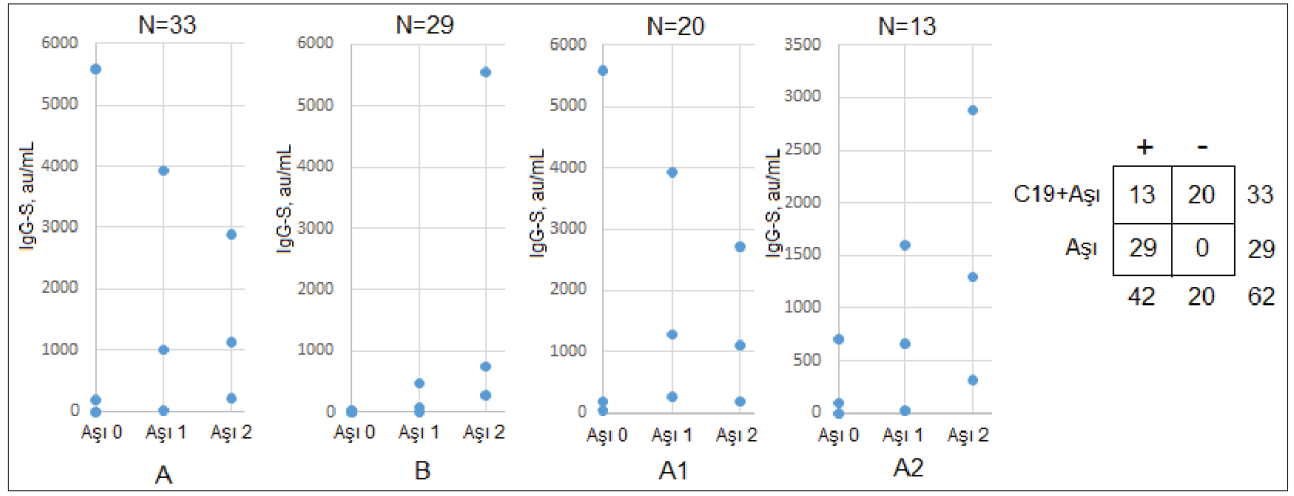

Şekil 1. Minimum, medyan ve maksimum antikor (Ab) ölçüm düzeyleri (toplam örnek sayısı=62). Yatay eksen: (Aşı 0) CoronaVac aşısı ile aşılama öncesi ölçülen Ab0 antikor düzeyleri, (Aşı 1) birinci aşıdan sonra ölçülen Ab1 antikor düzeyleri, (Aşı 2) ikinci aşıdan sonra ölçülen Ab2 antikor düzeyleri. A) Önceden hastalık geçiren ve sonra aşı olanlar (33 kişi), B) Hastalık geçirmeden aşılananlar (29 kişi), A1) Önceden hastalık geçiren ve aşı olanlardan 2. aşı sonrası antikor değeri düşenler (20 kişi), A2) Önceden hastalık geçiren ve aşı olanlardan 2. aşı sonrası antikor değeri artanlar (13 kişi). lyi anlaşılması için dikey eksen aralığı diğer grafik eksenlerinden daha düşük seçildi. Durum tablosu, her iki gruptaki değişimleri özetler. 


\section{KAYNAKLAR}

1. World Health Organization (WHO). WHO recommendation of Sinovac COVID-19 vaccine (Vero Cell [inactivated]) - CoronaVac. Available from: https://extranet.who.int/pqweb/vaccines/who-recommendationsinovac-covid-19-vaccine-vero-cell-inactivated-coronavac. (Accessed date: 3 Aug 2021)

2. Centers for Disease Control and Prevention (CDC). Interim clinical considerations for use of COViD-19 vaccines currently approved or authorized in the United States. Available on: https://www.cdc.gov/vaccines/covid-19/ info-by-product/clinical-considerations.html (Accessed date: 3 Aug 2021).

3. Saadat S, Rikhtegaran Tehrani Z, Logue J, Newman M, Frieman MB, et al. Binding and neutralization antibody titers after a single vaccine dose in health care workers previously infected with SARS-CoV-2. JAMA 2021; 325(14): 1467-69.

4. Krammer F, Srivastava K, Simon V, Alshammary H, Amoako AA, Awawda MH, Beach KF, et al. Antibody responses in seropositive persons after a single dose of sARS-CoV-2 mRNA vaccine. N Engl J Med 2021; 384(14): 137274.

5. Wise J. COVID-19: people who have had infection might only need one dose of mRNA vaccine. BMJ 2021; 372: n308. 